\title{
MONITORAMENTO DA QUALIDADE DA ÁGUA DO RIO CAVEIRAS NO PLANALTO SERRANO DE SANTA CATARINA COM SUPORTE DE TECNOLOGIAS DE GEOMÁTICA
}

\author{
CAVEIRAS RIVER WATER QUALITY MONITORING IN PLANALTO SERRANO \\ (SANTA CATARINA STATE) THROUGH GEOMATIC SUPPORT TECHNOL
}

\author{
MONITORAMENTO DE LA CALIDAD DE LA AGUA DEL RÍO CAVEIRAS \\ EN EL PLANALTO SERRANO DE SANTA CATARINA COMPATIBLE COM \\ TECNOLOGIAS DE GEOMÁTICA
}

\author{
Sílvio Luís Luís Rafaeli Neto - Universidade do Estado de Santa Catarina - \\ Florianópolis - Santa Catarina - Brasil \\ silvio@cav.udesc.br
}

Valter Antonio Becegato - Universidade do Estado de Santa Catarina - Lages - Santa Catarina - Brasil becegato@cav.udesc.br

João Batista Pereira Cabral - Universidade Federal de Goiás - Jataí - Goiás - Brasil

jbcabral2000@yahoo.com.br

\begin{abstract}
Resumo
0 monitoramento da qualidade da água em bacias hidrográficas possui forte componente espacial, uma vez que os locais de monitoramento distribuem-se no espaço geográfico. Em se tratando de bacias, em que o talvegue principal se estende por dezenas de quilômetros, há que se utilizar tecnologias de suporte ao planejamento dos locais de amostragem, definição de rotas de acesso e estudo do uso e da ocupação do solo como forma de subsidiar o processo de análise dos resultados. 0 rio Caveiras está situado na região serrana de Santa Catarina com uma bacia hidrográfica com cerca de $2400 \mathrm{~km}^{2}$. A jusante do seu terço superior, destaca-se a captação de água para 0 abastecimento da cidade de Lages, seguida de uma Pequena Central Hidrelétrica (PCH) com cerca de 2 MW de potência instalada. Em breve, serão construídas mais três PCHs a jusante da existente, formando uma sequência de quatro ambientes lênticos. Este trabalho tem por objetivo apresentar um estudo de caso de aplicação de tecnologias de Geomática no monitoramento da qualidade da água do rio Caveiras antes da construção das $\mathrm{PCH}$, como subsídio à avaliação dos impactos ambientais destes empreendimentos.

Palavras-chave: qualidade da água, impacto ambiental, uso do solo, bacia hidrográfica.
\end{abstract}

\section{Abstract}

The monitoring of water quality in river basins has strong spatial component as the local of monitoring are distributed about geographic space. In the case of basins where the principal watercourse extends for tens of kilometers, it is necessary to use technology to support the planning of sites for sampling, definition of routes of access and study the use and occupation of land as a way to subsidize the process of analyzing the results. The Caveiras river is located in a mountain region of Santa Catarina State with a catchment area of about 2,400 $\mathrm{km}^{2}$. Downstream of its upper third, it is the abstraction of water for the supply of the city of Lages, followed by a Small Hydroelectric Central (PCH) with approximately $2 \mathrm{MW}$ of installed power. Soon, three more will be built downstream of the existing PCHs, forming a sequence of four lentic environments. This paper aims to present a case study of application of technologies of Geomatics in the monitoring of water quality in the river before the construction of the PCHs as subsidy for environmental impact assessment of these ventures.

Key words: water quality, environmental impact, land use, watershed. 
Resumen

Monitoreo de la calidad del agua en las cuencas hidrográficas tienen fuerte componente espacial una vez que los puntos de monitoramento distribuen-se en el espacio geográfico. Cuando se trata de cuencas en que el talvegue principal abarca decenas de kilómetros, utilizar tecnologías de soporte de planificación de los puntos de muestreo, definición de rutas de acceso y estudio del uso y ocupación del suelo como medio de contribuir al proceso de análisis de los resultados. El río Caveiras está situado en la región montañosa de Santa Catarina con una cuenca con aproximadamente $2400 \mathrm{~km}^{2}$. A jusante de su tercio superior, se hace la captación de agua para el abastecimiento de la ciudad de Lages, seguida de una pequeña planta hidroeléctrica, con aproximadamente 2 MW de potencia instalada. Pronto se construirán tres represas de geración de energia a jusante de la existente formando una secuencia de cuatro ambientes de lénticos. Este trabajo pretende presentar un estudio de caso de aplicación de las tecnologías de Geomática en el monitoramento de la calidad del agua del río Caveiras antes de la construcción de represas, como subsidio a la evaluación del impacto ambiental de estas plantas energéticas. Palabras clave: la calidad del água, impacto ambiental, uso de la tierra, cuenca.

Introdução

Geomática é um termo recente para designar o conjunto de ciências que estudam as componentes espaciais dos fenômenos geográficos. Alguns autores a designam por Ciência da Informação Geo-espacial (Xu, Wei, Ruan, 2002), cujos conceitos são oriundos de Sistemas de Posicionamento por Satélites, Sistemas de Informação Geográfica e Sistemas de Sensoriamento Remoto. As tecnologias de Geomática, portanto, são utilizadas para coletar, medir, analisar, armazenar, gerenciar, exibir e distribuir geodados (Rafaeli Neto, 2003), ou seja, dados que possuem referências espaciais.

Monitoramentos da qualidade da água em rios e lagos requerem definição dos locais de amostragens, definição das rotas de acessos e conhecimento sobre o uso e ocupação do solo da sub-bacia de contribuição de cada ponto. As dificuldades aumentam na medida da dimensão da bacia hidrográfica e da extensão do talvegue principal. Estes problemas são de natureza espacial, cuja solução depende de informações sobre as entidades espaciais envolvidas. Tecnologias de Geomática podem ser aplicadas nestas situações, fornecendo os geodados necessários ao suporte à decisão.

A bacia hidrográfica do rio Caveiras (Figura 1) está situada na região serrana de Santa Catarina, sendo a segunda maior sub-bacia da bacia hidrográfica do rio Canoas.

Estima-se que a qualidade das suas águas esteja mais comprometida num trecho de $70 \mathrm{~km}$, o qual se inicia com o ponto de captação de água que abastece a cidade de Lages para uma população de 160.000 ha- 
bitantes. O terço superior do rio, a montante deste ponto, é considerado classe 1 (Seplan, 1977), onde convivem comunidades rurais esparsas e a cidade de Painel, com cerca de 2500 habitantes. A jusante deste ponto, o rio recebe os efluentes industriais de uma cervejaria e efluentes urbanos de Lages, principalmente através dos rios Ponte Grande $\left(24 \mathrm{~km}^{2}\right)$ e Carahá $\left(30 \mathrm{~km}^{2}\right)$ (Rafaeli Neto, 1994).

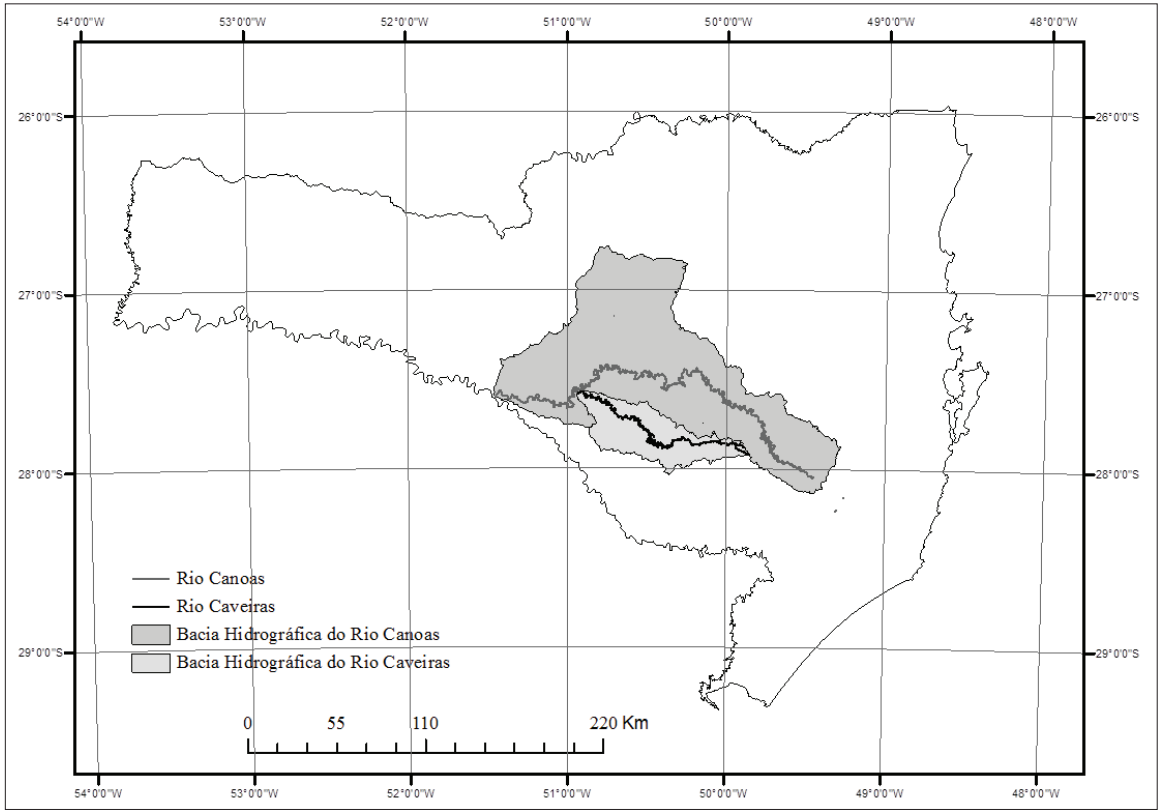

Figura 1 - Localização da bacia hidrográfica do rio Caveiras.

Na sequência de seu trajeto, o rio é represado pela Pequena Central Hidrelétrica (PCH) Salto Caveiras, cujo lago, com cerca de $12 \mathrm{~km}^{2}$ de superfície, serve também para recreação de contato direto nos dias de calor e para atividades econômicas de uma comunidade instalada ao seu redor. Além destes usos, estão para serem construídas à jusante mais três represas (ANEEL, 2005a, 2005b e 2005c) para geração de energia. Os aproveitamentos hidrelétricos (Figura 2) Itararé (10 MW de potência instalada), João Borges (19 MW) e Pinheiro (10 MW), deverão estar com o início da montagem dos canteiros de obras e acampamentos instalados até Dezembro de 2009. Estas quatro PCHs comporão uma sequência de ambientes 
lênticos, com cerca de $20 \mathrm{~km}^{2}$ de lago, que podem alterar as características lóticas do rio no trecho das três novas usinas.

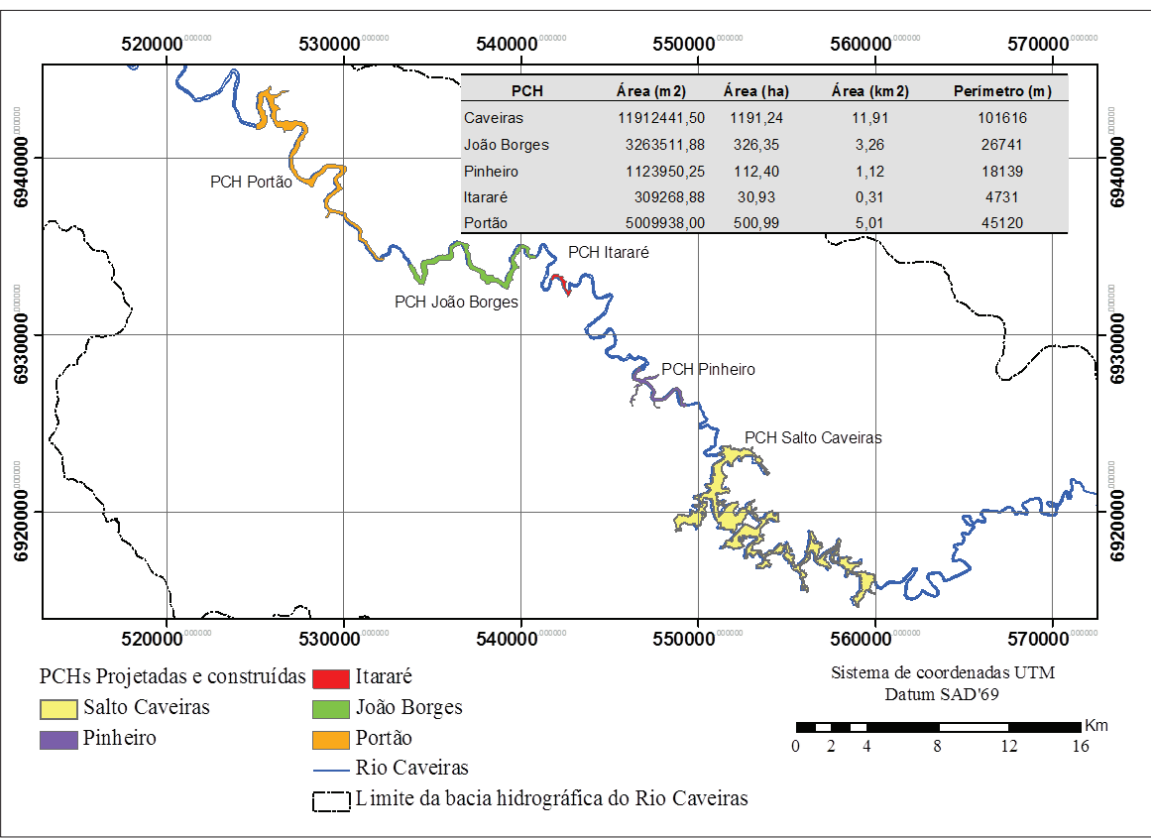

Figura 2 - Localização das PCHs Salto Caveiras (já construída), Pinheiro, Itararé, João Borges e Portão, ao longo do rio Caveiras.

Esta pesquisa teve por objetivo apresentar a utilização de tecnologias de Geomática aplicadas ao monitoramento da qualidade da água de um rio com extensão de $250 \mathrm{~km}$, antes da instalação de três PCHs, como meio de fornecer subsídios aos processos de negociação sobre prováveis passivos ambientais destes empreendimentos; bem como investigar a influência antrópica na qualidade da água deste importante rio para a região Serrana de Santa Catarina. 
Material e métodos

Base de dados geográficos

O banco de geodados foi construído a partir de folhas topográficas do IBGE editadas pela EPAGRI/CIRAM, nas escalas 1:100.000 e 1:50.000, imagens multiespectrais LANDSAT TM de Outubro de 2004 e imagens QUICKBIRD $(0,6 \mathrm{~m})$ do Google Earth. O divisor de águas que delimita a bacia hidrográfica, as curvas de nível e a rede de drenagem foram utilizadas a partir da base de dados construída por Rafaeli Neto (1994). As áreas alagadas das PCHs projetadas foram obtidas da Secretaria de Estado de Desenvolvimento Regional de Lages. Este material foi reunido no Sistema de Informações Geográficas SPRING, padronizado no datum horizontal SAD'69. As imagens de satélites foram submetidas a um processo de georreferenciamento e posteriormente a tratamentos de realce e classificação supervisionada. Para a classificação foram utilizados como pontos de controles conhecimentos empíricos da região, pontos coletados em sobrevoo de helicóptero em maio de 2008, pontos oriundos do Google Earth e pontos disponíveis na base de dados do Laboratório de Geoprocessamento do Departamento de Engenharia Ambiental da UDESC-Campus de Lages.

A partir do banco de geodados foi realizado estudo de planejamento dos pontos de amostragem e das rotas de acessos. As coordenadas dos pontos a serem visitados nas campanhas de reconhecimento foram inseridas em receptores GPS de navegação. Foram elaborados croquis de campo indicando possíveis rotas e a localização "provável" dos pontos a serem visitados. O termo "provável" está colocado no sentido de que a base de dados 1:100 000 está eivada de erros, o que se confirmou no trabalho de campo.

Duas campanhas de reconhecimento foram necessárias para explorar as rotas de acessos e definir os pontos de amostragem durante $\mathrm{o}$ monitoramento.

\section{Definição dos pontos de amostragem}

Os pontos de amostragem (Figura 3) distribuíram-se ao longo do rio. O ponto NASC foi estabelecido sobre uma ponte e considerado como ponto de controle, supostamente sendo o que apresentaria os melhores valores dos parâmetros de qualidade da água, especialmente por estar 
na região de cabeceira da bacia e seu entorno apresentar pouca atividade antrópica. O ponto PAINEL receberia influência do terço-superior do rio Caveiras, considerado de Classe 1 conforme resolução do Conama n. 357 (Brasil, 2005).

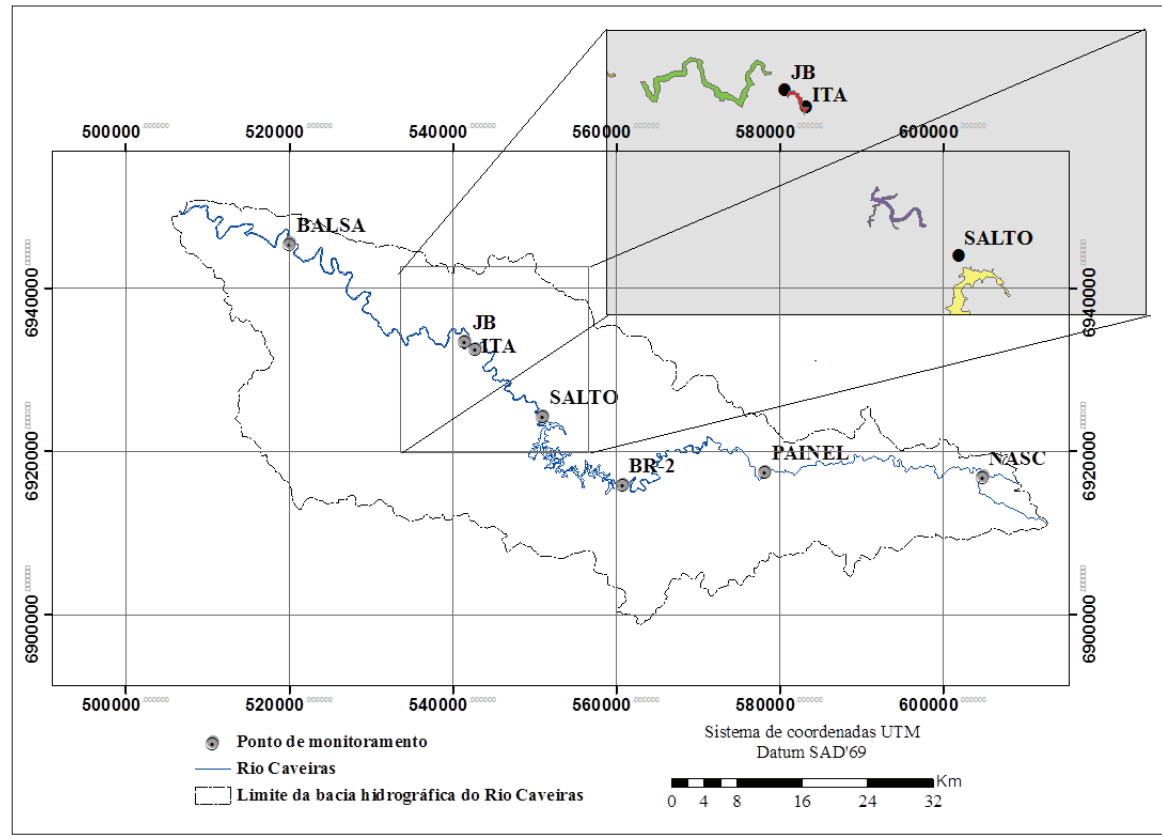

Figura 3 - Localização dos pontos monitorados ao longo do rio Caveiras de agosto/2008 a dezembro/2008.

O ponto BR-2 receberia influência das cargas poluidoras de uma cervejaria, dos rios Ponte Grande e Caraha e ainda da região oeste da cidade que despeja seus efluentes numa série de rios que deságuam no rio Caveiras. Este ponto possui especial relevância porque antecede o lago do Salto do Rio Caveiras, utilizado para gerar energia elétrica pela PCH das Centrais Elétricas de Santa Catarina (CELESC) e também pela comunidade de Santa Teresinha do Salto que vive no seu entorno. O ponto SALTO está localizado após a estação de geração da CELESC e recebe influência do alagado. Os pontos BR-2 e SALTO deveriam permitir uma compreensão dos efeitos de um alagamento na qualidade da água do rio. 
Para os pontos ITA, JB e BALSA o critério de localização foi que o ponto deveria estar no trecho compreendido entre a casa de força de uma PCH e o lago da PCH a jusante. Isto porque este trecho do rio deverá manter-se como ambiente lótico, mesmo após a construção destas usinas, de tal modo que, futuramente seja dada continuidade ao monitoramento para comparação com o período pré-usinas. Assim, para a PCH Pinheiro estabeleceu-se a montante de seu lago o ponto SALTO e a jusante de sua casa de força o ponto ITA. Para a PCH Itararé tem-se a montante do lago o ponto ITA e a jusante da casa de força o ponto JB. Para a PCH João Borges tem-se a montante do lago o ponto JB.

Não foi possível estabelecer um ponto entre o lago da PCH Portão e a casa de força da João Borges por inexistência de acesso a este trecho. Assim, foi estabelecido o ponto BALSA, após a casa de força da PCH Portão, a $26 \mathrm{~km}$ da foz do rio Caveiras no rio Canoas.

\section{Campanhas de reconhecimento e amostragem de campo}

Nos dias 18/7/2008 e 24/7/2008 foram realizadas campanhas de campo para reconhecimento durante as quais foram analisados os acesso às margens e centro do rio, tempo necessário para fazer os percursos e retornar a Lages de modo a enviar as amostras ao laboratório, custo da campanha de campo (Figura 4). Durante essas campanhas, foram feitos ensaios de amostragem composta, ou seja, com repetição em três pontos na seção transversal do rio (margens e centro). Foram efetuadas medições das variáveis: oxigênio dissolvido, sólidos dissolvidos, condutividade e salinidade. Os resultados preliminares não indicaram diferenças significativas, razão de se ter adotado amostragem simples, o mais próximo possível ao centro do rio.

Cinco campanhas de monitoramento foram realizadas em sete pontos ao longo do rio, nas seguintes datas: 28 e 29/8/2008; 18/9/2008; 4/11/2008; 25/11/2008 e 11/12/2008. As amostragens obtidas a partir do dia $4 / 11$ foram precedidas de períodos de chuvas intensas. As amostragens dos dias 28 e 29/8 foram precedidas de período de longa estiagem. A partir do dia 18/9 todos os pontos foram amostrados num único dia, sendo as amostras mantidas em caixas térmicas com gelo.

Procurou-se seguir uma rotina de campo de modo que o horário de coleta de uma amostra fosse a mesma ao longo das campanhas. A razão 
principal dessa decisão está no fato de que alguns parâmetros, como o oxigênio dissolvido, dependem da temperatura da água. Entretanto, a sazonalidade provocou aumento da temperatura dos meses mais frios para os meios mais quentes.

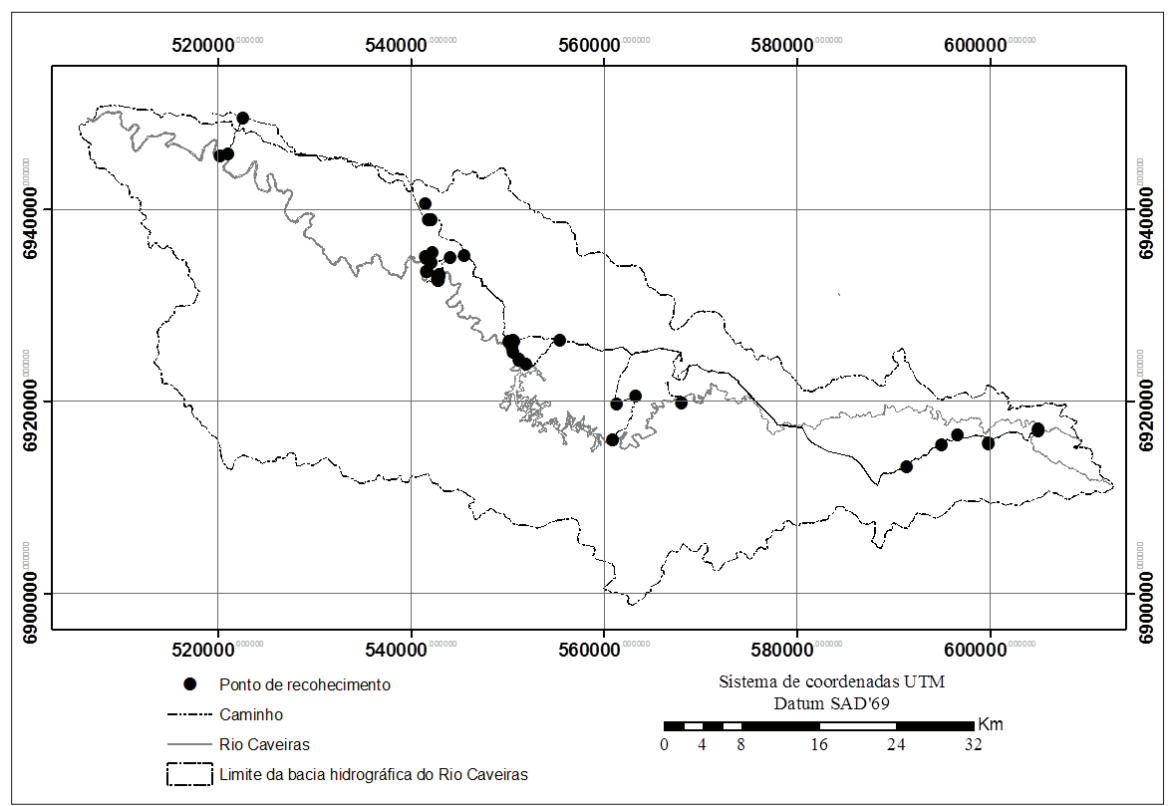

Figura 4 - Localização dos pontos monitorados ao longo do rio Caveiras de agosto/2008 a dezembro/2008.

Parâmetros de qualidade da água e métodos de análises

Os parâmetros que foram definidos para análise da qualidade da água foram os seguintes: $\mathrm{pH}$, oxigênio dissolvido, salmonelas, coliformes fecais, coliformes totais, nitrogênio amoniacal, nitrito, nitrato, sulfato, cloreto, fósforo total, DBO, DQO, condutividade, sólidos dissolvidos, salinidade. Os dois primeiros foram determinados a campo. Realizaram-se calibrações prévias em laboratório com soluções próprias, antes de cada campanha de amostragem. Para salmonelas, coliformes fecais e coliformes totais, optou-se pela utilização de cartela com meio de cultura, submetida à estufa a $37^{\circ} \mathrm{C}$ por $24 \mathrm{~h}$. Após este tempo foram contadas as co- 
lônias indicadas por pontos azuis (coliformes fecais), verdes (salmonelas) e vermelhos. Estes últimos, somados aos azuis, compuseram o número de colônias de coliformes totais. Sua concentração (em UFC/100mL) foi obtida multiplicando-se o número de colônias por 60 , conforme orientação do fabricante. Condutividade, sólidos dissolvidos e salinidade somente puderam ser medidos com sonda durante as campanhas de reconhecimento, por ser um equipamento emprestado e não disponibilizado nas campanhas seguintes. Os demais parâmetros foram determinados no Laboratório de Pesquisas Hidrogeológicas (LPH) da Universidade Federal do Paraná.

\section{Resultados e discussão}

A Tabela 1 apresenta as áreas e perímetros das sub-bacias de contribuições dos pontos de monitoramento. Na Figura 5 estão ilustrados os polígonos de representação de acordo com a sequência ao longo do rio.

Tabela 1 - Áreas de contribuição e perímetros das sub-bacias dos pontos monitorados ao longo do rio Caveiras de agosto/2008 a dezembro/2008.

\begin{tabular}{ccccc}
\hline Ordem no rio & Código do local & Área $\left(\mathrm{km}^{2}\right)$ & $\begin{array}{c}\text { Área Total } \\
(\%)\end{array}$ & $\begin{array}{c}\text { Perímetro } \\
(\mathrm{km})\end{array}$ \\
\hline 1 & NASC & 36,1 & 1,5 & 28,1 \\
2 & PAINEL & 352,2 & 14,5 & 111,3 \\
3 & BR-2 & 798,6 & 33,0 & 193,1 \\
4 & SALTO & $1.036,7$ & 42,8 & 220,2 \\
5 & ITA & $1.361,1$ & 56,2 & 245,9 \\
6 & JB & $1.367,5$ & 56,4 & 247,0 \\
7 & BALSA & $2.231,3$ & 92,1 & 325,0 \\
\hline Área total da bacia & & 2.423 & & \\
\hline
\end{tabular}



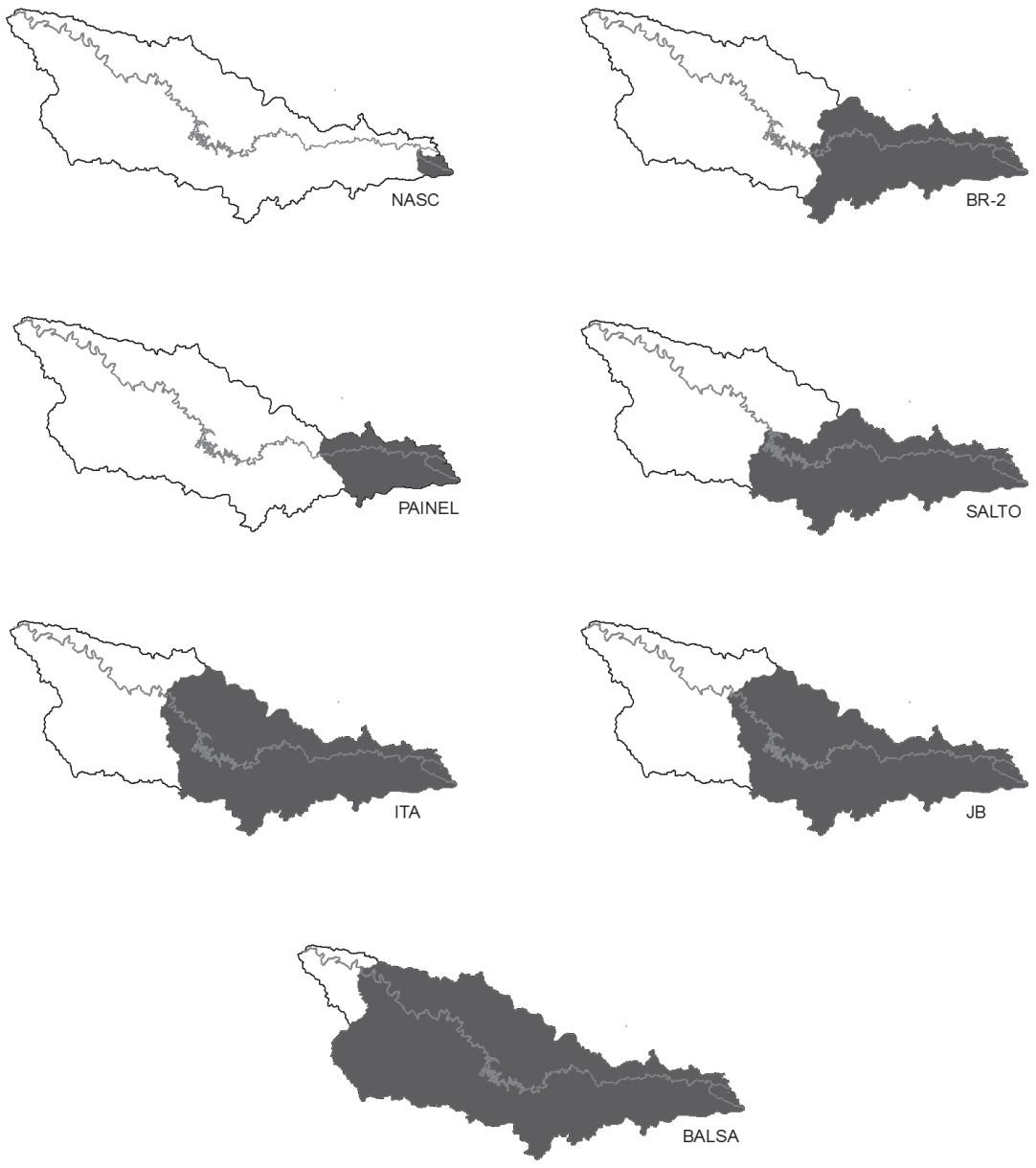

Figura 5 - Sub-bacias de contribuição dos pontos de amostragens da água ao longo do rio Caveiras.

Uso e ocupação do solo das sub-bacias de contribuições

As classes de uso e ocupação (Figura 6) definidas foram: Campo, Floresta, Reflorestamento, Agricultura, Núcleo Urbano, Solo Exposto e Água-corpo hídrico. 
A sub-bacia do ponto NASC é a que apresenta o maior índice de floresta $(82,6 \%)$. A jusante deste ponto, o índice de floresta diminui gradativamente até atingir $36,7 \%$ da área da sub-bacia respectiva. As áreas de Campo representam de 40 a 50\% da área da sub-bacia, e os reflorestamentos de 4 a 5\%. As áreas de núcleos urbanos são mais significativas na sub-bacia do ponto BR-2, especialmente representadas pelo núcleo urbano da cidade de Lages. Este dado vem reforçar a constatação de que a deterioração nos parâmetros de qualidade da água neste ponto, em relação aos demais, se deve aos efluentes desta cidade.

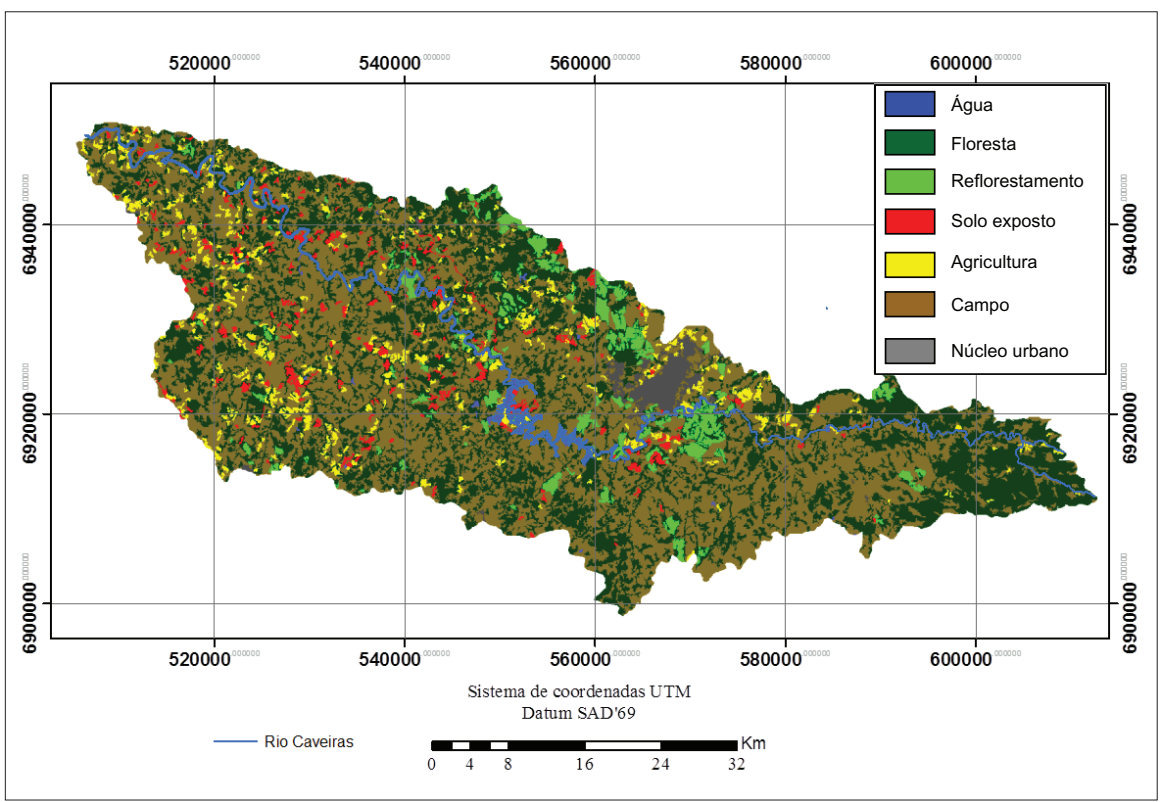

Figura 6 - Ocorrência de classes de uso e ocupação do solo na bacia hidrográfica do rio Caveiras - outubro/2004.

As áreas de solo exposto possuem uma correlação (Figura 7) altamente significativa com as áreas de agricultura. Fato análogo também foi observado por Becegato et al. (2007) na região metropolitana de Curitiba, PR. O coeficiente de determinação indica que cerca de 98\% das áreas de solo exposto são, na verdade, áreas de agricultura, as quais se encontravam parcialmente cobertas pela vegetação, em pousio, ou em fase de preparo do solo durante a tomada da imagem satelitária. 


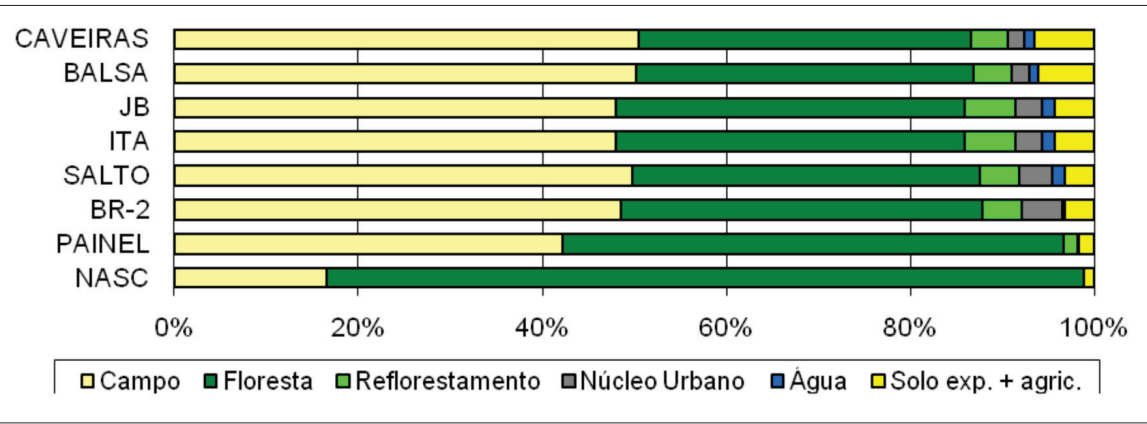

Figura 7 - Percentual das classes de uso e ocupação do solo em relação à área de drenagem da bacia do rio Caveiras e sub-bacias dos pontos de monitoramento - outubro/2004.

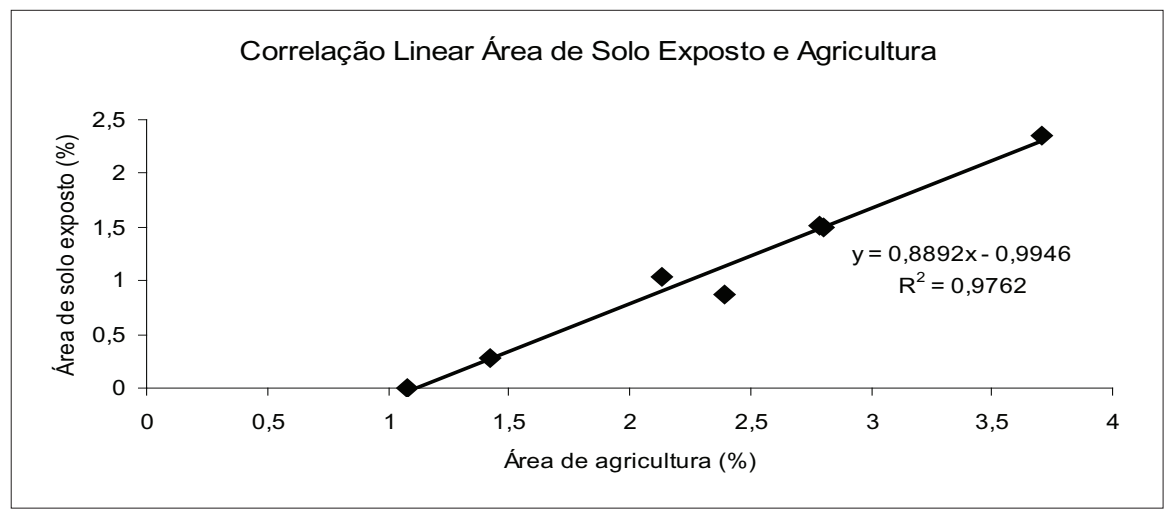

Figura 7 - Correlação entre os índices de solo exposto e agricultura nas sub-bacias dos pontos de monitoramento.

Efeito das precipitações sobre os parâmetros analisados

Alguns parâmetros analisados apresentaram correlações significativas com o volume acumulado de precipitações a partir de 10 dias antes da data de amostragem (Tabela 2). Destaque para os parâmetros DBO e DQO que apresentaram altas correlações negativas, indicando uma provável diluição da carga orgânica poluente com o aumento da vazão do rio. 
Tabela 2 - Correlações entre os valores médios dos parâmetros de qualidade da água e a precipitação acumulada nos 10 dias anteriores à coleta das amostragens.

\begin{tabular}{lccccccc}
\hline Ponto & NASC & PAINEL & BR-2 & SALTO & ITA & JB & BALSA \\
\hline OD & $-0,03$ & 0,02 & 0,45 & 0,19 & 0,03 & $-0,02$ & $-0,03$ \\
C. Fecais & $-0,89$ & 0,36 & 0,52 & 0,53 & 0,75 & 0,69 & 0,29 \\
C.Totais & $-0,67$ & $-0,24$ & $-0,43$ & 0,87 & 0,00 & 0,00 & 0,51 \\
Salmonelas & - & $-0,44$ & 0,24 & 0,84 & 0,96 & $-0,44$ & 0,79 \\
DBO & - & $-1,00$ & $-0,61$ & $-0,05$ & $-0,99$ & $-0,99$ & $-0,53$ \\
DQO & - & $-0,30$ & $-0,64$ & $-0,25$ & $-0,99$ & $-0,91$ & $-0,49$ \\
Temp.Sonda & $-0,33$ & $-0,44$ & $-0,51$ & $-0,52$ & $-0,48$ & $-0,36$ & $-0,45$ \\
Nitrato & 0,75 & 0,92 & $-0,55$ & 0,51 & 0,25 & 0,28 & 0,38 \\
N Amoniacal & - & $-0,40$ & $-0,68$ & 0,80 & 0,64 & 0,70 & 0,46 \\
Nitrito & - & - & $-0,88$ & 0,20 & 0,39 & 0,39 & 0,39 \\
P Total & 0,01 & 0,47 & $-0,49$ & $-0,13$ & 0,86 & 0,25 & 0,39 \\
Cloreto & $-0,18$ & $-0,73$ & $-0,88$ & $-0,09$ & $-0,22$ & $-0,44$ & 0,05 \\
\hline
\end{tabular}

A carga de coliformes fecais tendeu a aumentar em todos os pontos de amostragem, na medida do aumento do volume de chuvas, com exceção do ponto NASC. A correlação positiva parece estar relacionada com o uso e ocupação do solo das demais sub-bacias, em que o escoamento superficial devido às precipitações conduziu esta carga poluidora até o rio. No ponto NASC isto não ocorreu, provavelmente por sua sub-bacia estar predominantemente ocupada por mata nativa bem preservada.

Os parâmetros nitrogenados também tenderam a crescer com o volume precipitado, com exceção do ponto BR-2, que representa o ponto mais crítico em termos de poluição, situado logo após o núcleo urbano de Lages. O aumento pode estar relacionado com a ocorrência de áreas agrícolas, indicando um aporte de formas nitrogenadas oriundas de adubações de culturas anuais levadas ao rio pelo escoamento superficial, fato também constatado por (Machado, Becegato, Bittencourt, 2009) estudando a bacia do rio Branco, PR. No caso do ponto BR-2 as correlações negativas indicam a diluição das mesmas.

\section{Correlações entre períodos de amostragens}

A grande maioria dos valores médios dos parâmetros de qualidade da água obtidos nas cinco campanhas de amostragens apresentaram correlações lineares significativas ao nível de 5\% (Figura 8). A pouca variação entre os mesmos, ao longo do período de amostragem, indica uma homegeneidade dos dados no período de agosto de 2008 a dezembro de 2009. 


\begin{tabular}{|c|c|c|c|c|c|}
\hline \multicolumn{6}{|c|}{ NASC } \\
\hline & $29 / 08 / 08$ & $18 / 09 / 08$ & $04 / 11 / 08$ & $25 / 11 / 08$ & $11 / 12 / 08$ \\
\hline $29 / 08 / 08$ & 1,00 & 0,86 & 0,74 & 0,89 & 0,99 \\
\hline $18 / 09 / 08$ & & 1,00 & 0,98 & 0,83 & 0,92 \\
\hline $04 / 11 / 08$ & & & 1,00 & 0,70 & 0,83 \\
\hline $25 / 11 / 08$ & & & & 1,00 & 0,89 \\
\hline $11 / 12 / 08$ & & & & & 1,00 \\
\hline \multicolumn{6}{|c|}{ BR-2 } \\
\hline & $29 / 08 / 08$ & $18 / 09 / 08$ & $04 / 11 / 08$ & $25 / 11 / 08$ & $11 / 12 / 08$ \\
\hline $29 / 08 / 08$ & 1,00 & 0,76 & 0,75 & 0,95 & 0,74 \\
\hline $18 / 09 / 08$ & & 1,00 & 1,00 & 0,92 & 0,16 \\
\hline $04 / 11 / 08$ & & & 1,00 & 0,91 & 0,15 \\
\hline $25 / 11 / 08$ & & & & 1,00 & 0,52 \\
\hline $11 / 12 / 08$ & & & & & 1,00 \\
\hline \multicolumn{6}{|c|}{ ITA } \\
\hline & $29 / 08 / 08$ & $18 / 09 / 08$ & $04 / 11 / 08$ & $25 / 11 / 08$ & $11 / 12 / 08$ \\
\hline$\overline{29 / 08 / 08}$ & 1,00 & 0,99 & 0,75 & 0,99 & 1,00 \\
\hline $18 / 09 / 08$ & & 1,00 & 0,82 & 0,99 & 1,00 \\
\hline $04 / 11 / 08$ & & & 1,00 & 0,74 & 0,78 \\
\hline $25 / 11 / 08$ & & & & 1,00 & 0,99 \\
\hline $11 / 12 / 08$ & & & & & 1,00 \\
\hline \multicolumn{6}{|c|}{ BALSA } \\
\hline & $29 / 08 / 08$ & $18 / 09 / 08$ & $04 / 11 / 08$ & $25 / 11 / 08$ & $11 / 12 / 08$ \\
\hline $29 / 08 / 08$ & 1,00 & 1,00 & 0,89 & 0,32 & 0,83 \\
\hline $18 / 09 / 08$ & & 1,00 & 0,89 & 0,32 & 0,82 \\
\hline $04 / 11 / 08$ & & & 1,00 & 0,33 & 0,99 \\
\hline $25 / 11 / 08$ & & & & 1,00 & 0,32 \\
\hline $11 / 12 / 08$ & & & & & 1,00 \\
\hline
\end{tabular}

\begin{tabular}{|c|c|c|c|c|c|}
\hline \multicolumn{6}{|c|}{ PAINEL } \\
\hline & $29 / 08 / 08$ & $18 / 09 / 08$ & $04 / 11 / 08$ & $25 / 11 / 08$ & $11 / 12 / 08$ \\
\hline $29 / 08 / 08$ & 1,00 & 1,00 & 1,00 & 1,00 & 1,00 \\
\hline $18 / 09 / 08$ & & 1,00 & 1,00 & 1,00 & 1,00 \\
\hline 04/11/08 & & & 1,00 & 1,00 & 1,00 \\
\hline 25/11/08 & & & & 1,00 & 1,00 \\
\hline $11 / 12 / 08$ & & & & & 1,00 \\
\hline \multicolumn{6}{|c|}{ SALTO } \\
\hline & $29 / 08 / 08$ & $18 / 09 / 08$ & $04 / 11 / 08$ & $25 / 11 / 08$ & 11/12/08 \\
\hline $29 / 08 / 08$ & 1,00 & 0,79 & 0,95 & 0,48 & 0,84 \\
\hline $18 / 09 / 08$ & & 1,00 & 0,94 & 0,54 & 0,99 \\
\hline $04 / 11 / 08$ & & & 1,00 & 0,54 & 0,96 \\
\hline $25 / 11 / 08$ & & & & 1,00 & 0,61 \\
\hline $11 / 12 / 08$ & & & & & 1,00 \\
\hline \multicolumn{6}{|c|}{ JB } \\
\hline & $29 / 08 / 08$ & $18 / 09 / 08$ & $04 / 11 / 08$ & $25 / 11 / 08$ & $11 / 12 / 08$ \\
\hline $29 / 08 / 08$ & 1,00 & 0,99 & 0,73 & 1,00 & 0,99 \\
\hline $18 / 09 / 08$ & & 1,00 & 0,82 & 0,99 & 1,00 \\
\hline 04/11/08 & & & 1,00 & 0,73 & 0,81 \\
\hline 25/11/08 & & & & 1,00 & 0,99 \\
\hline $11 / 12 / 08$ & & & & & 1,00 \\
\hline
\end{tabular}

Figura 8 - Coeficientes de correlação linear entre os valores médios dos parâmetros de qualidade da água medidos nas cinco campanhas de monitoramento.

\section{Qualidade da água ao longo do rio}

Os comportamentos dos parâmetros de qualidade da água ao longo dos pontos amostrados mostraram-se variados (figuras 9 a 13). Em geral, sofreram piora do ponto NASC ao ponto BR-2. A partir deste último, houve tendência de melhoria, indicando o efeito provável de dois fatores principais: a ação do lago do Salto Caveiras, que pode estar retendo a carga poluidora da cidade de Lages, e a ação de reaeração de inúmeras corredeiras ao longo do rio.

Seria esperado que o ponto NASC, localizado no alto da bacia, apresentasse os melhores índices de qualidade da água. O oxigênio dissolvido apresentou-se bem acima do limite mínimo de $5 \mathrm{mg} / \mathrm{L}$ estabelecido pela Resolução Conama n. 357 para rio de classe 1 (Brasil, 2005). Surpreenderam os níveis de coliformes e salmonelas bem acima de 1000 UFC/100mL em $80 \%$ das amostras, estabelecidos pela mesma resolução. Considerando que representa apenas $1,5 \%$ da área total da bacia do rio Caveiras $(36,1$ 
$\mathrm{km}^{2}$ ), a causa provável estaria na presença de algumas edificações esparsas e na criação de animais, especialmente pecuária extensiva. Quanto aos parâmetros biológicos de DBO e DQO, os resultados laboratoriais deste ponto não apresentaram valores consistentes para análise, diferentemente de Machado, Becegato e Bittencourt (2006), que, em estudos realizados na bacia do rio Pinheiro no estado do Paraná, obtiveram valores significativos sinalizadores de aporte de carga orgânica. As concentrações de nitritos resumiram-se a traços menores que $0,01 \mathrm{mg} / \mathrm{L}$ (limite de $1 \mathrm{mg} / \mathrm{L}$ ) em todo o período de amostragem. As concentrações de fósforo total também estiveram abaixo do limite de $0,1 \mathrm{mg} / \mathrm{L}$, assim como de nitrogênio amoniacal, (limite de $10 \mathrm{mg} / \mathrm{L}$ ) e de cloreto (limite de $250 \mathrm{mg} / \mathrm{L}$ ).

Os parâmetros analisados no ponto PAINEL apresentaram comportamentos semelhantes ao ponto NASC, com uma tendência geral de indicarem uma melhor qualidade geral da água. Este comportamento não seria esperado uma vez que sua área de contribuição é cerca de 10 vezes maior que a do ponto NASC e possui em seu interior a cidade de PAINEL com cerca de 2500 habitantes. A explicação para isso estaria no fato de que, apesar de suas dimensões em relação ao ponto NASC, a sub-bacia do ponto PAINEL é muito pouco antropisada. Além disso, o afluente do rio Caveiras que receberia diretamente os efluentes desta cidade, e o próprio rio Caveiras, estariam fazendo a autodepuração numa extensão de cerca de $20 \mathrm{~km}$ desde a cidade de Painel ao ponto de amostragem.

Foi confirmada a hipótese inicial de que a qualidade da água no ponto BR-2 seria inferior à dos demais pontos. Os níveis de oxigênio dissolvido mantiveram-se dentro do limite para rio classe $2(<5 \mathrm{mg} / \mathrm{L})$, confirmando a constatação de que, apesar da carga de poluentes, o rio Caveiras possui grande capacidade de reaeração. Este comportamento natural poderia ser comprometido com o represamento sistemático previsto com as PCH's projetadas.

O comportamento dos parâmetros de qualidade da água do ponto SALTO pode ser comparado com o comportamento dos parâmetros do ponto BR-2, uma vez que entre os mesmos se encontra o lago do Salto Caveiras. O oxigênio dissolvido não sofreu variações significativas entre $o$ ponto BR-2 e SALTO, provavelmente devido à queda d'água até a casa de força, que estaria agindo como reaerador a jusante do lago.

O comportamento dos parâmetros de qualidade da água no ponto ITA parecem pouco diferir dos pontos anteriores. Haveria uma pequena 
melhora nos parâmetros microbiológicos, especialmente no que se refere a coliformes fecais e salmonelas. Os parâmetros de DBO e DQO não mostraram boa consistência, mas parecem indicar tendência de DBO entre 2 a $5 \mathrm{mg} / \mathrm{L}$, dentro dos limites para rios classe 2 .

O comportamento do ponto JB assemelhou-se ao do ponto ITA, como seria esperado, por serem pontos muito próximos entre si ao longo do rio. Destaca-se que, a exemplo dos pontos SALTO e ITA, houve uma tendência de diminuição das concentrações dos parâmetros nitrogenados e de fósforo total, embora todos estivessem sempre dentro dos limites aceitáveis para rios da classe 1.

Seria esperado que o ponto BALSA apresentasse melhores condições de qualidade da água que os demais pontos, por estar bem distante das principais fontes pontuais de poluição. Entretanto, seu comportamento parece diferir mais apenas no que se refere aos parâmetros nitrogenados. Os parâmetros biológicos indicam que sua ocorrência estaria mais relacionada com a extensão da área de contribuição e com o uso do solo.

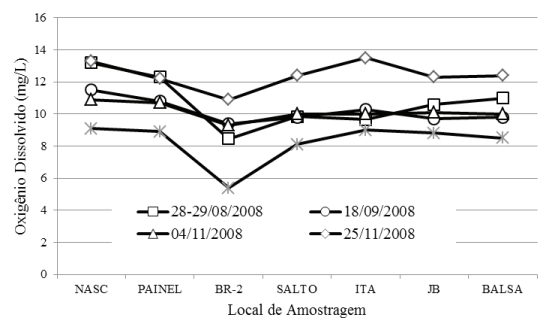

Figura 9 - Comportamento do oxigênio dissolvido (mg/L) ao longo dos pontos amostrados.

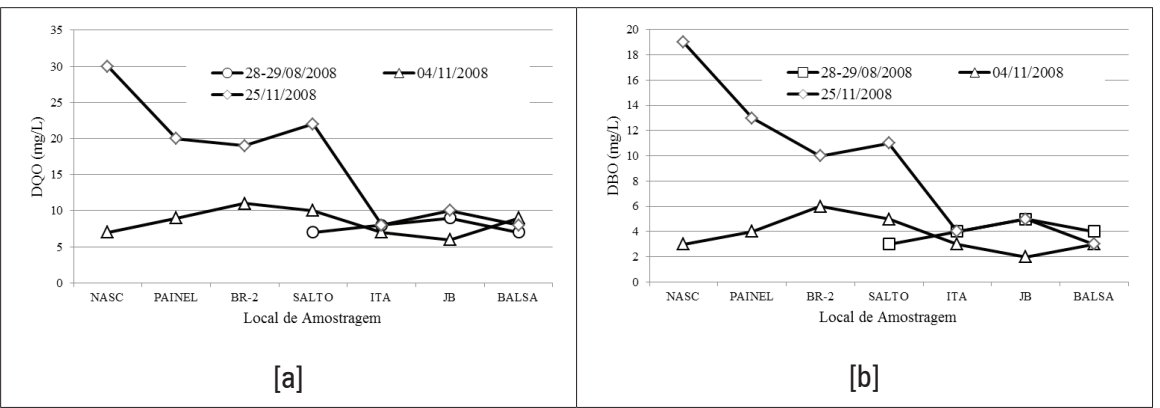

Figura 10 - Comportamento da [a] DOO (mg/L) e [b] DBO (mg/L) ao longo dos pontos amostrados. 


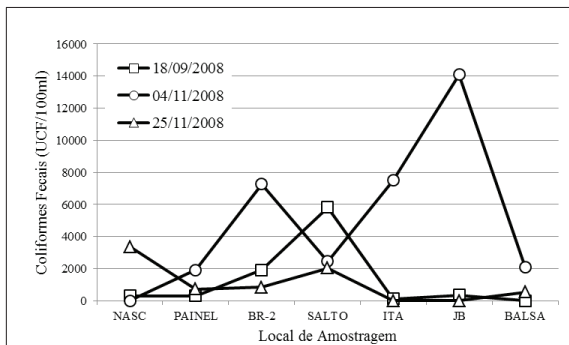

[a]

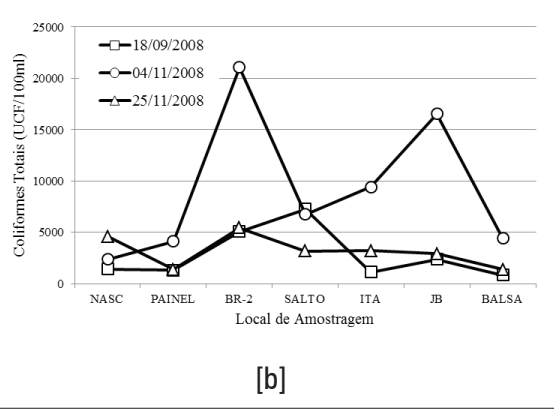

Figura 11 - Comportamento de coliformes (UFC/100ml) [a] fecais e [b] totais ao longo dos pontos amostrados.

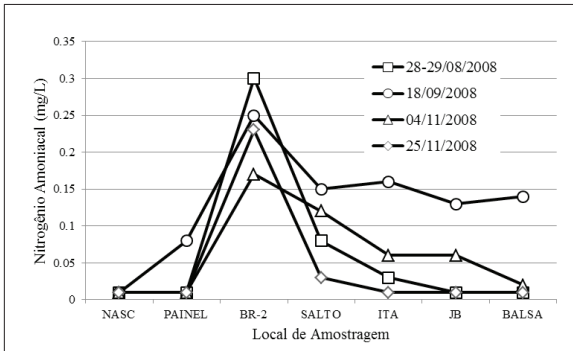

[a]

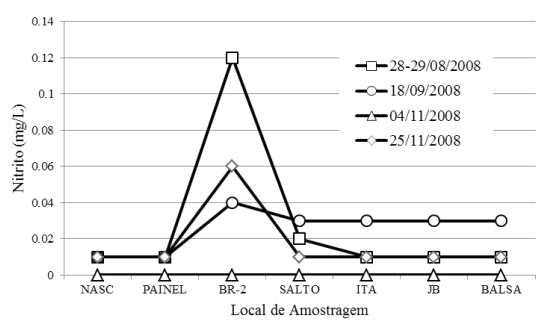

[b]

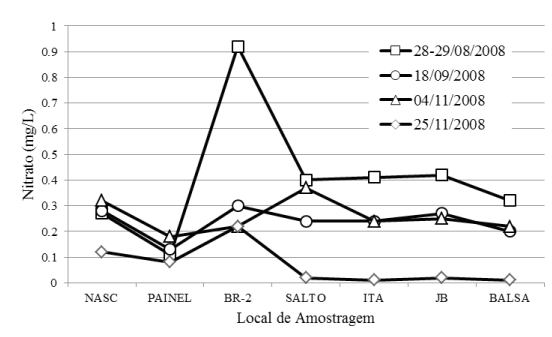

[c]

Figura 12 - Comportamento de [a] nitrogênio amoniacal (mg/L), [b] nitrito (mg/L) e [c] nitrato (mg/L) ao longo dos pontos amostrados. 


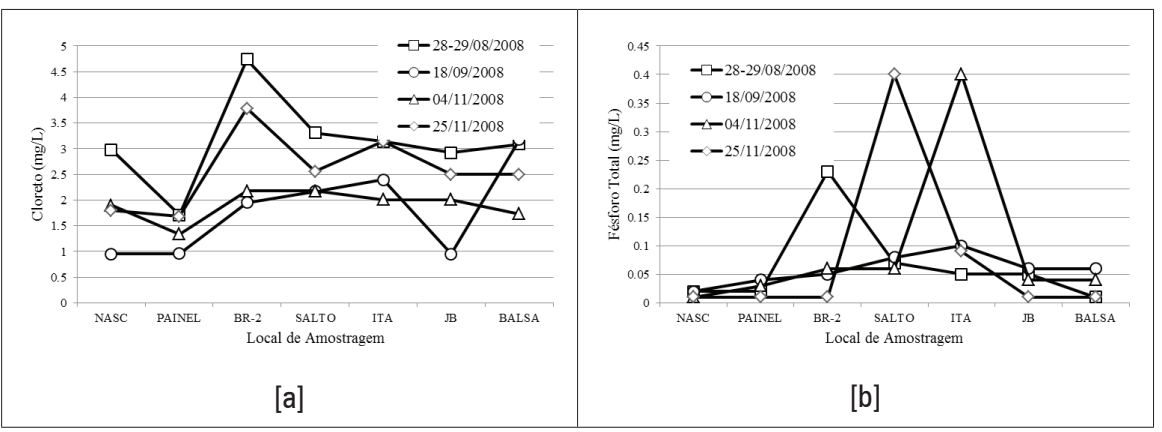

Figura 13 - Comportamento de [a] cloreto (mg/l) e [b] fósforo total (mg/L) ao longo dos pontos amostrados.

\section{Conclusões}

As tecnologias de Geomática mostraram-se úteis nas etapas de planejamento dos locais de amostragem, no mapeamento e na quantificação das classes de uso e ocupação do solo da bacia e na delimitação e quantificação das áreas de contribuição dos pontos de amostragem. Os dados geográficos obtidos com a Geomática foram importantes auxiliares na interpretação dos parâmetros de qualidade da água e na identificação de prováveis causas dos valores encontrados.

Por se tratar de um período chuvoso, houve correlações significativas entre os parâmetros de qualidade da água e as precipitações acumuladas nos 10 dias anteriores à amostragem. Os parâmetros nitrogenados tenderam a crescer com o aumento das precipitações pluviométricas, exceto no ponto BR-2.

Os parâmetros avaliados comportaram-se de modo diversificado ao longo dos pontos amostrados. Identificou-se uma tendência de piora dos valores junto ao ponto BR-2 e traços de melhoria a partir do ponto SALTO, o que indicaria uma provável ação de retenção de carga poluidora pela PCH Salto Caveiras.

Os níveis de coliformes e salmonelas apresentaram valores acima de 1000 UFC/100 ml em 80\% das amostras.

\section{Agradecimentos}

Os autores expressam seus agradecimentos à Udesc, Fapesc, Polícia Militar Ambiental de Santa Catarina e ao colega Glênio Bruck de Andrade. 


\section{Referências}

ANEEL, 2005a. Disponível em: <http://www.aneel.gov.br/cedoc/area2005373_1. pdf (PCH Itararé)>. Acesso em: 9 jun. 2009.

ANEEL, 2005b. Disponível em: <http://www.aneel.gov.br/cedoc/area2005375_1. pdf. (PCH Pinheiro)>. Acesso em: 9 jun. 2009.

ANEEL, 2005c. Disponível em: <http://www.aneel.gov.br/cedoc/area2005374_1. pdf (PCH João Borges)>. Acesso em: 9 jun. 2009.

BECEGATO, V. A. et al. Monitoramento do uso e ocupação do solo em área de influência do município de Fazenda Rio Grande - região metropolitana de Curitiba, PR. RA'E GA, n. 14. p. 217-226, 2007.

BORGES, K. A. V. Modelagem de dados geográficos: uma extensão do modelo OMT para aplicações geográficas. Dissertação (Mestrado em Administração Pública) Fundação João Pinheiro, Belo Horizonte, 1997.

BRASIL. CONAMA - Conselho Nacional do Meio Ambiente. Resolução n. 357, 2005. Disponível em: <http//WWW.mma.gov.br>. Acesso em: 9 jun. 2009.

EPAGRI - Empresa de Pesquisa Agropecuária e Extensão Rural de Santa Catarina. Disponível em: <http://www.epagri.rct-sc.br/epagri/>. Acesso em: jan. 2006.

MACHADO, W. C. P.; BECEGATO, V. A.; BITTENCOURT, A. V. Monitoramento ambiental da qualidade da água do rio Pinheiro - um afluente na bacia hidrográfica do rio Pato Branco, PR. Revista de Estudos Ambientais, v. 8, n. 2, p. 44-63, 2006.

MACHADO, W. C. P.; BECEGATO, V. A.; BITTENCOURT, A. V. Anthropic influence in the water quality of the river basin that supplies the Pato Branco Municipality-PR. Brazilian Archives of Biology and Technology, v. 52, n. 1, p. 221232, 2009.

RAFAELI NETO, S. L. Análises morfométricas em bacias hidrográficas integradas a um sistema de informações geográficas. Dissertação (Mestrado) - Departamento de Geociências, Universidade Federal do Paraná, Curitiba, 1994.

RAFAELI NETO, S. L. Desafios e perspectivas para integração de geomodelos a geodados. In: 2a. Conferencia Ibero-americana in Sistemas, Cibernética e Informática - CISCI, 2003, v. 1, p. 121-125. Orlando: International Institute of Informatics and Systemics, 2003.

RAFAELI NETO, S. L.; SILVA, J. B. Modelagem conceitual de geodados com técnica orientada-a-objetos para a outorga do direito de uso de recursos hídricos. Revista Brasileira de Recursos Hídricos, v. 11, p. 235-244, 2006.

SEPLAN - Secretaria de Estado de Planejamento e Coordenação de Santa Catarina. Portaria n. 024/77.

XU, S.; WEI, Z.; RUAN. X. A telegeomatics-based environmental survey and information service system. In: Pecora15/Land Satellite Information IV/ISPRS Commission I/FIEOS, 2002. Conference Proceedings, 10 a 15 de novembro de 2002, Denver, CO, USA. 
Sílvio Luís Luís Rafaeli Neto - Possui graduação em Agronomia pela Universidade do Estado de Santa Catarina, mestrado em Ciências Geodésicas pela Universidade Federal do Paraná e doutorado em Engenharia pela Universidade de São Paulo, 2000. Atualmente é professor Associado e subchefe do Departamento de Engenharia Ambiental da Universidade do Estado de Santa Catarina.

Valter Antonio Becegato - Possui Graduação em Agronomia pela Universidade do Estado de Santa Catarina, mestrado em Ciência do Solo pela Universidade Federal do Paraná e doutorado em Geologia Ambiental pela Universidade Federal do Paraná. Atualmente é professor Associado da Universidade do Estado de Santa Catarina.

João Batista Pereira Cabral - Possui graduação em Geografia pela Faculdade de Filosofia Ciências e Letras Imaculada Conceição, mestrado em Geociências e Meio Ambiente pela Universidade Estadual Paulista Júlio de Mesquita Filho e doutorado em Geologia pela Universidade Federal do Paraná. Atualmente é professor adjunto da Universidade Federal de Goiás.

Recebido para publicação em 21 de outubro de 2012 Aceito para publicação em 1 de fevereiro de 2013 